\title{
An Empirical Research of Chinese Learners' Acquisition of the English Article System - Based on Syntactic Misanalysis Account
}

\author{
Shi Jian ${ }^{1}$ \\ ${ }^{1}$ College of Humanities and Foreign Languages, Xi'an University of Science and Technology, China \\ Correspondence: Shi Jian, College of Humanities and Foreign Languages, Xi'an University of Science and \\ Technology, Lintong District, Xi'an Shaanxi 710600, China. E-mail: smith168@126.com
}

Received: January 15, 2013 Accepted: February 7, 2013 Online Published: March 10, 2013

doi:10.5539/elt.v6n4p56 URL: http://dx.doi.org/10.5539/elt.v6n4p56

\begin{abstract}
In the field of applied linguistics, the English article is the acknowledged teaching and learning difficulty and receives lots of attention in second language acquisition (SLA). This paper, based on the Syntactic Misanalysis Account (SMA) advocated by Trenkic in which L2 articles are analyzed as adjectives by L2ers, proposes the English article is the functional category with null semantic meaning and its production is syntactic-driven. The English Proficiency Test and the Forced Choice Elicitation Task have been conducted with 41 freshmen, 41 sophomores and 41 juniors of English majors in Xi'an University of Science and Technology (XUST), which finds L2ers from L1 Chinese maybe relate referential meaning of definite to the perceptible referent but the meaning of indefinite to the non-recognizable referent and thus produce substitution errors in their English article choices.
\end{abstract}

Keywords: English Article System, SLA, SMA, ACP, ESK

\section{Introduction}

The English article system comprises the definite article the, the indefinite article a/an and the null (or "zero") article $\varnothing$, which modify the noun phrase (NP), representing the semantic meaning of definiteness, specificity etc., to develop the complex semantic concepts, the unique syntactic functions and the complicated matching relations between form and meaning. The English articles are the most frequently used parts of speech in spoken and written English output. For us, every L2 English learner, although we are usually taught to learn by rote several grammatical rules about the usage of the English articles in the English elementary lessons, we can not completely master them until a rather late stage during the course of L2 English acquisition. So the grasp of English articles for the L2 learners from article-less L1 is none of easy job at all. It may cause the most advanced non-native speakers of English to commit mistakes even when all the other ingredients of the language have already been grasped (Master, 1990). What's more, it poses even greater difficulty for learners whose mother tongue has no functional counterparts of the English definite and indefinite article (Master, 1987; Berry, 1991). Mandarin Chinese is commonly deemed as a language without particle equivalents of the English article system. The semantic meaning of definiteness and indefiniteness in Chinese language are labeled by the arranging of word order or the using of determiners (Robertson, 2000). Therefore, the acquisition of English articles becomes a huge obstacle to the L2ers from the L1 Chinese background.

The accessibility of the Universal Grammar (UG) has long been the central issue of SLA studies based on the generative grammar theory. The L2 syntactic impairment research, which centers around the UG accessibility, has shifted its focus from such functional category as the verb inflectional suffixes like the simple present tense third person singular marker, the bound morpheme, to the free morpheme, the English articles. (Changhui, 2009) So considerable L2 acquisition studies as regards English article omission and substitution have been carried out in recent years to attest whether the linguistic factor like Article Choice Parameters (ACP) or the extra-linguistic factor like Explicitly Stated Knowledge (ESK) plays a role in L2ers' article choice, which both remain controversial in the previous literature. The most dominant views among those researches are the Fluctuation Hypothesis (FH) adopted by Ionin et al. (2004), and the Syntactic Misanalysis Account (SMA) supported by Trenkic $(2007,2008)$.

To be reckoned with the above-mentioned practical and theoretical reasons, the current research focuses mainly on the article substitution errors, in which the definite context needs the and the indefinite context requires $a$. 
The production of substitution errors signals how the L2ers understand what the English articles are in their mental lexicons and how to represent the articles in their L2 grammars.

\section{Background of the Study}

\subsection{UG Grammar and its Accessibility in SLA}

UG, the initials of Universal Grammar, is advanced by the well-known contemporary American linguist Noam Chomsky. He interprets UG as follows: "the system of principles, conditions and rules that are elements or properties of all human languages."(1976: 29). Chomsky (1981a) generalizes that the language universals consist of principles and parameters. The term "principles" refers to the extremely metaphysical attributes of grammar which can be applied to all natural languages generally and underlie all the individual natural languages rules. The term "parameters" refers to principles that can be various between and among languages by certain strict and rigid means. Parameters have two or more "settings", with different languages manifesting different settings (Rod Ellis, 1994). It maintains the interlocutor masters a series of principles that can be applied to all natural languages and parameters that can be changeable within clearly defined limits from one language to another. Thus, to acquire a certain natural language is to learn how such principles are applied to a specific language and which value is proper for each of the parameters (Cook, 2002).The question that whether L2ers have direct and full access to UG or even not or partial and indirect access perhaps remains to be the hot issues of researches among those who are committed to applying the principles and parameters of UG theory to the practice of SLA. Due to the differentiations in both initial and end states of L2 learning, Cook (1985) put forward three possibilities in relation to UG accessibility: The first one is that L2ers start from scratch; they have direct access to UG and are uninfluenced by the L1 (direct and full accessibility); The second one is that L2ers start from their knowledge of the first language and they have indirect access to UG via the L1 (indirect accessibility); and the third possibility is that L2ers do not treat L2 as a language at all; they have no access to UG and learn the L2 totally without its help (no accessibility).

\subsection{UG Accessibility in English Article Acquisition}

Ionin et al. (2004) takes side with the direct accessibility, holding that mistakes in L2ers' English articles option production are not haphazard but actually demonstrate L2ers' full and direct access to the ACP: the universally binary semantic differentiations of definiteness and specificity. Mr. Dai Weidong and Mrs. Wei li (2007) tested the FH proposed by Ionin et al. (2004); However, their results showed the Chinese learners did not fluctuate between the two features of the ACP: definiteness and specificity; Instead, the Chinese L2ers could acquire the definiteness setting successfully while specificity had no effect on article choice, which did not confirm that of Ionin et al. (2004).

Contrary to Ionin et al. (2004), Trenkic (2008) proposes that the L2ers' errors in English article choices production can not trigger UG principles and have no direct access to the setting or mis-setting of the semantic parameters: specificity and definiteness. She advanced the SMA where English articles are analyzed and understood as adjectives by L2ers in their mental lexicons and the English article is the functional category with null semantic meaning and its production is syntactic-driven. The present study adopts the SMA hypothesis that in their article choices, L2ers are interfered by a non-semantic, non-UG-determined syntactic factor, taking a new variable ESK into consideration.

\subsection{The Operational Definition of Variables: Specificity, Definiteness, ESK}

\subsubsection{Specificity}

Specificity is commonly talked about in relation to the indefinite NP. Here specificity is restricted to the discourse specificity, the speaker's purpose to speak of a certain referent, which is the working definition for the variable specificity in the present paper, instead of the speaker specificity.

An intent to talk about an entity presupposes the interlocutor must already have a specific referent in his or her mind. However, merely possessing a precise referent in the speaker's mind is not adequate to categorize the context into referential, and request a specific article to match, which is exemplified in (1) and (2):

(1) I'm hungry. Please pass me an apple!

(2) A lady asked me how to get to the railway station on the street this morning.

In (1), the interlocutor doesn't own a special referent in mind and any apple would be ok, so this context is obviously labeled as [-spec].However, what confuses us in (2) is that the context still remains [-spec], and still the indefinite article $a$ is chosen, even if the interlocutor must have a peculiar referent in mind. Obviously the speaker has encountered face-to-face with the lady in question and he surely knows a lot of information of her: 
her appearance, her approximate age, her accent, education level, social status and manners etc. What assumes problematic here is that in spite of there existing a unique referent for the interlocutor (speaker specificity), its uniqueness is of no importance or relevance for the conversation going on. To certain extent, the interlocutor maybe has no intent to mention something more of the woman in question, and didn't anticipate the interlocutor setting up an additional conversation referent. For the sake of clarity, here we'd better differentiate the discourse specificity from the speaker's specificity.

\subsubsection{Definiteness}

The term of definiteness has already been elaborated widely and profoundly in the literatures of semantics, pragmatics, syntactic and discourse analysis, from the perspective of both form and function. Taking a universally cognitive point of view, Trenkic (2008) assumes that definiteness might be signaled by the using definite articles in some languages. Definiteness is closely connected with the recognizability of the referents in conversation.

Just like specificity, definiteness is a conversation-relative conception too. Specificity merely emphasizes the perspective of the interlocutor: the interlocutor has a peculiar referent in his or her mind and intends to speak of it. Definiteness, however, adds to specificity another perspective of the hearer: if the interlocutor possesses a special referent in mind and has an intention to mention it, at the same time the speaker expects the referent to be singularly recognizable to the hearer as well, then the conversation referent is unambiguous. Definiteness, the discourse referent identifiability, might be interpreted in all languages either obtained from some parts of lexical-semantic constituent of the linguistic expressions or deduced from the situations of communication. Any NP context across all natural languages could be grouped into definite and non-definite. Most natural languages infer definiteness pragmatically while some employ the obvious grammatical markers to signal definiteness. (Trenkic, 2008)

The morphological expressions of the feature [+definite] and [-definite] in the English article system are represented by means of the functional element the and $a$ respectively. According to Heim (1991), we consider the as being specified for definiteness, and $a$ as being underspecified [+definite]. Put it in another way, the can be chosen correctly when and solely when it meets the requisites for definiteness, while $a$ does not ask for such requirements. Consequently, If such requisites for definiteness have been satisfied, the is opted. Whenever these conditions haven't been reached, $a$ is employed. Let's examine the following illustration (3):

\section{(3) I finished reading a book. And I think the book is informative.}

When firstly speaking of $a$ book, there exists no presupposition that an unparalleled book subsists; therefore the requisites for definiteness (the interlocutor and the hearer both presuppose the subsistence of an unparalleled individual in the set denoted by the NP) haven't been satisfied. Thus, the indefinite article $a$ is selected. Contrastingly speaking, when secondly mentioning of the same book, the subsistence of a peculiar and single book (the individual one which has just been talked about) has been taken hold. Since the requisites for definiteness have been satisfied, the is chosen.

The once-mention in the previous discourse or the second emergence of the same entity in the discourse, however, does not always necessarily establish the unique identifiability. Under certain circumstances, the presupposition condition for uniqueness is reached due to the shared world knowledge (the common sense) between the interlocutor and the hearer. This is shown by example (4):

\section{(4) The champion of today's competition will receive a gold inlaid with jade medal.}

For the definite article in (4) "The champion" to be properly used, it is not always true that the interlocutor and the hearer should be speaking of some particular or salient champion (a specific individual). The world knowledge tells us that any competition must have only one champion and the unique identifiability presupposing condition is met here. So the definite article the is supplied in this context.

\subsubsection{ESK}

Trenkic(2008) introduced an innovative design to propose that the role of the parameter specificity on L2ers' article options (full and direct access to UG) is better depicted as an influence or interference of the overtly stated or denied acquaintance with the referent ,i.e. the variable of ESK, an extra-linguistic factor, having nothing to do with the UG parameters. Supposing the meanings L2ers assign to article forms are not constrained by UG, Trenkic(2008) put forward that "definite" and "indefinite" are, as a matter of fact, the lexical meanings L2ers analyzing and treating English articles as adjectives have such a semantic match with the linguistic symbols as listed below: 
the: adj, definite (that can be identified)

$a(n):$ adj, indefinite(that cannot be identified)

Let's see the instance (5)

(5) In a dean office

Visitor: I'd like to meet dean smith. Would you please let me in?

Secretary: I'm very sorry that he is quite busy right now.

Visitor: What is he busy with?

Secretary: He has an emergency to deal with at present, but I don't know what it is.

The interlocutor (secretary) denies that she is familiar with the referent (an emergency), so the context is grouped as [-spec]. Obviously, Ionin et al. (2004) confuses the definition of discourse specificity (the interlocutor possessing a referent in mind and also having an intention to speak of it to the hearer) with that of ESK (the interlocutor's overt announcement of his acquaintance with the referent being mentioned). Whether the specificity or ESK exerts an effect in L2ers' article choice is not clear yet and whether specificity, being one parameter of ACP related to UG can be triggered or not, both of which remains questions to be tested.

\section{Research Methodology}

\subsection{Subjects}

The subjects in this study were 123 English majors from XUST, among whom 41 are freshmen, 41 are sophomores and 41 are juniors, which are also the natural grouping of grades. They range in age from 17 to 23 and the age mean is 20.58. All the subjects have studied English for at least 6 years before they take English as their majors. In the university, they attend English classes of all sorts 20 to 30 hours per week and self-teach themselves 6 to 10 hours each week. The English majors recruiting score in XUST belongs to the second class in China although some of the subjects excel in English.

\subsection{Instruments}

All of the subjects are required to take two written tests: one is the forced-choice elicitation task of English article use in short conversations and the other is a cloze test of L2ers language skills assessment following the forced-choice elicitation task.

\subsubsection{Language Proficiency Test}

The language proficiency test, namely the English language skills assessment (ELSA), was a short cloze test consisting of 25 multiple-choice items. Subjects were asked to complete the test with a time limit (20 min.). The purpose was to test the participant's English proficiency and to categorize them into different groups based on their performance.

\subsubsection{The Forced-Choice Elicitation Test}

The elicitation test material encompasses twenty four short situational conversations adapted from the issues in the forced-choice elicitation task by Ionin et al. (2004). Amid the conversation, there is a blank right before the intended NP, where the subjects are required to fill, making a choice among the three given options: the, $a$ and zero article -. All the intended NPs are singular forms and the amount of definite and indefinite linguistic situations was halved, with 12 in each.

To test whether specificity affects the L2ers' article choices in the elicitation task or the explicitly stated/denied acquaintance with the recognizing attributes of the entity being spoke of, the plus and minus value of definiteness is crossed with three associations of specificity and ESK values, thus six linguistic situations arising as follows:

Type 1: [-Definite], [+Specific, +ESK]

Type 2: [-Definite], [-Specific, -ESK]

Type 3: [-Definite], [+Specific, -ESK]

Type 4: [+Definite], [+Specific, + ESK $]$

Type 5: [+Definite], [-Specific, -ESK]

Type 6: [+Definite], [+Specific, -ESK]

There are altogether 24 situational dialogues in the elicitation task and each context type was exemplified by 4 
different conversations.

\subsection{Procedures}

Firstly the forced choice elicitation task was administered in the classroom with the help of the colleagues at their lectures. After the question papers were handed out to the subjects, the investigator (I) asked the subjects to judge whether the, $a$ or the zero article - would be chosen to fill in the gap just on their intuitions and reminded them that this was not a test or quiz to reduce their anxiety. Also require all the subjects to write down their personal information like age, gender and names on the questionnaire. The subjects were allotted 25 minutes to finish the task, but most of them completed within 15 approximately minutes. And then the English Language skills assessment test was conducted. Just as mentioned above, the cloze test with 25 items was required to complete with the time limit of 20 min., but most of them finished the entire test within 10 min. Consequently, the investigator collected all the test papers and filed them according to grades and tests.

\subsection{Data Analysis}

The language proficiency test - the cloze papers were marked after the task and the total 123 subjects were divided into three groups from Grade 1 (G1) to Grade 3 (G3) according to their scores on ELSA: 46 advanced, 43 upper intermediate $=(\mathrm{u}$ intermediate $)$ and 34 intermediate. One-way ANOVA was performed and their descriptive statistics is summarized in Table 1:

Table 1. Participant's descriptive statistics

\begin{tabular}{lccccc}
\hline Group & $G 1+G 2+G 3=N$ & Mean & $S D$ & Min & Max \\
\hline Advanced & $11+18+17=46$ & 22.1304 & 1.2580 & 21.00 & 25.00 \\
Upper Intermediate & $14+16+13=43$ & 18.8372 & .7847 & 18.00 & 20.00 \\
Intermediate & $16+6+12=34$ & 15.9412 & 1.3244 & 12.00 & 17.00 \\
Total & $41+41+41=123$ & 19.2683 & 2.7403 & 12.00 & 25.00 \\
\hline
\end{tabular}

The ANOVA result shows there is remarkable influence of group $(F(2,122)=294.728, p<.001)$, and multiple comparisons show there lies conspicuous differentiation between the groups $(\mathrm{p}<.001)$.

As to the raw data of the forced choice elicitation task, we enter them twice. The first time we log data into the software EXCEL according to the subject's natural grade (freshmen, sophomore and junior) and the second time we input data based on the language proficiency group (advanced, upper intermediate and intermediate). And then, the proportions of overuse and proper use of $a$ and that of the were calculated in the six different context types and all scores of article use were analyzed with the aid of the computer software SPSS.

\section{Results and Discussion}

\subsection{Results of the Advanced Group}

Table 2. Advanced group's correct use of articles

\begin{tabular}{lccccc}
\hline Definiteness & \multicolumn{2}{c}{$\begin{array}{c}\text {-definite } \\
\text { Correct use of a } \\
\text { Use of Article }\end{array}$} & Mean $\%$ & $S D$ & \multicolumn{2}{c}{ Correct use of the } \\
Context & 93.48 & .1703 & Mean $\%$ & SD \\
\hline$[-\mathrm{spec} ;-\mathrm{ESK}]$ & 86.41 & .1803 & 76.63 & .2322 \\
{$[+\mathrm{spec} ;+\mathrm{ESK}]$} & 91.85 & .1297 & 85.33 & .1793 \\
{$[+\mathrm{spec} ;-\mathrm{ESK}]$} & & 61.41 & .2280 \\
\hline
\end{tabular}

ANOVA found no difference among the three combinations in indefinite contexts $F(2,135)=2.411$, $p=.094$, but significant effect for definite contexts, $F(2,135)=14.649, \mathrm{p}<.001$. Multiple comparisons show that the correct use of the in [+spec; -ESK] environments is conspicuously more than that either of [+spec; +ESK] environments $(\mathrm{p}<.001)$ or of $[-\mathrm{spec} ;-\mathrm{ESK}]$ environments $(\mathrm{p}=.004)$ and there is no difference between $[+$ spec; +ESK] environments and $[-\mathrm{spec} ;-\mathrm{ESK}]$ environments $(\mathrm{p}=.115)$. 
Table 3. Advanced group's overuse of articles

\begin{tabular}{|c|c|c|c|c|}
\hline \multirow{2}{*}{$\begin{array}{l}\text { Definiteness } \\
\text { Use of Article } \\
\text { Context }\end{array}$} & \multicolumn{2}{|c|}{$\begin{array}{c}\text {-definite } \\
\text { overuse of the }\end{array}$} & \multicolumn{2}{|c|}{$\begin{array}{c}+ \text { definite } \\
\text { overuse of } a\end{array}$} \\
\hline & Mean $\%$ & $S D$ & Mean $\%$ & $S D$ \\
\hline [-spec; -ESK] & 2.72 & .1205 & 14.67 & .1942 \\
\hline [+spec; +ESK $]$ & 12.50 & .1728 & 5.43 & 1168 \\
\hline [+spec; -ESK $]$ & 6.52 & .1110 & 29.89 & .2274 \\
\hline
\end{tabular}

In order to decide the influence of the variable association of specificity and ESK values on the use of the vs. $a$, a repeated measure analysis of variance (ANOVA) was conducted on the overuse of the in the in-definite situations, and the overuse of $a$ in definite situations according to the different combinations of context types. The association of specificity and ESK values had a highly remarkable influence on article use and overuse, whether the or $a$ received the measurement. Mauchly's test indicated that the supposition of sphericity was broken in definite contexts $\left(\chi^{2}(2)=8.264, \mathrm{p}=.014\right)$; thereby degrees of freedom (df) were adjusted using Greenhouse-Geisser estimate of sphericity $(\varepsilon=.60)$. Sphericity wasn't violated in indefinite environments.

The outcomes indicate that the overuse of the in indefinite environments was remarkably influenced by the association of specificity and ESK values, $\mathrm{F}(2,135)=5.919, \mathrm{p}=.003$. Contrasts displayed that overuse of the in $[+$ spec; +ESK] indefinite environments was remarkably more than in [-spec; $-\mathrm{ESK}]$ environments $(\mathrm{p}=.004)$, but not remarkably more than in [+spec; $-\mathrm{ESK}]$ environments $(\mathrm{p}=.118)$, confirming the argument that the overuse of the is connected with the plus value of specificity.

Overuse of $a$ in definite environments was also remarkably influenced by the association of specificity and ESK values, $\mathrm{F}(2,135)=20.417, \mathrm{p}<.001$. Contrasts exhibit that the overuse of $a$ was merely marginally less in definite [+spec; +ESK] environments than in [-spec; $-\mathrm{ESK}]$ environments, $\mathrm{p}=.061$, but remarkably less than in [+spec, $-\mathrm{ESK}]$ environments, $\mathrm{p}<.001$. This is against our prediction that the overuse of $a$ would be connected with the minus value of specificity. And the outcomes also show that the overuse of $a$ was remarkably less in [-S, $-\mathrm{ESK}]$ environments than in $[+\mathrm{S},-\mathrm{ESK}]$ environments $(\mathrm{p}=.001)$. The Overuse of a is shown to be more tied up with the combination of the negative value of ESK and the positive value rather than the negative value of specificity for the advanced group.

\subsection{Results of the Upper Intermediate Group}

Table 4. Upper Intermediate group's correct use of articles

\begin{tabular}{lccccc}
\hline Definiteness & \multicolumn{2}{c}{-definite } & \multicolumn{3}{c}{+ definite } \\
Use of Article & \multicolumn{2}{c}{ Correct use of a } & \multicolumn{2}{c}{ Correct use of the } \\
Context & Mean \% & $S D$ & Mean \% & SD \\
\hline [-spec; -ESK] & 94.19 & .1069 & 66.28 & .2721 \\
[+spec; +ESK] & 84.88 & .2123 & 80.23 & .2082 \\
[+spec;-ESK] & 91.86 & .1786 & 56.98 & .2335 \\
\hline
\end{tabular}

ANOVA found no difference among the three combinations in indefinite contexts $F(2,126)=3.421, p=.036$, and multiple comparisons reveal that there exists only remarkable differentiation between [-spec; $-\mathrm{ESK}]$ and $[+$ spec; + ESK] environments $(p=.046)$. The univarate test yielded significant effect for definite contexts, $F(2,126=10.280$, $\mathrm{p}<.001)$. Multiple comparisons show that the correct use of the in $[+\mathrm{spec} ;+\mathrm{ESK}]$ environments is remarkably more than that either of $[-$ spec; $-\mathrm{ESK}]$ environments $(\mathrm{p}=.029)$ or of $[+$ spec; $-\mathrm{ESK}]$ environments $(\mathrm{p}<.001)$.

Table 5. Upper intermediate group's overuse of articles

\begin{tabular}{|c|c|c|c|c|}
\hline $\begin{array}{l}\text { Definiteness } \\
\text { Use of Article }\end{array}$ & \multicolumn{2}{|c|}{$\begin{array}{c}\text {-definite } \\
\text { overuse of the }\end{array}$} & \multicolumn{2}{|c|}{ +definite } \\
\hline Context & Mean \% & $S D$ & Mean \% & $S D$ \\
\hline [-spec; -ESK] & 4.07 & .0934 & 21.51 & .2352 \\
\hline$[+$ spec; +ESK $]$ & 13.37 & 2137 & 04.07 & .0811 \\
\hline$[+$ spec; - ESK $]$ & 5.23 & .1286 & 34.30 & .1891 \\
\hline
\end{tabular}


The outcomes display that the overuse of the in indefinite contexts was remarkably influenced by the association of specificity and ESK values, $\mathrm{F}(2,126)=4.671, \mathrm{p}=.011$. Contrasts exhibited that overuse of the in $[+\mathrm{spec}$; $+E S K]$ indefinite environments was remarkably more than in [-spec; $-E S K]$ environemnts, $(p=.022)$, but only marginally more than in $[+$ spec; - ESK $]$ environments $(\mathrm{p}=.051)$, again confirming the argument that the overuse of the is connected with the plus value of specificity.

Overuse of $a$ in definite environments was also remarkably influenced by the association of specificity and ESK values, $\mathrm{F}(2,126)=32.921, \mathrm{p}<.001$. Contrasts display that the overuse of $a$ was remarkably less in definite $[+$ spec; + ESK $]$ environments than in $[-$ spec; - ESK $]$ environments and $[+$ spec, - ESK $]$ environments, $p<.001$. This is against our prediction that the overuse of $a$ would be connected with the minus value of specificity. And the outcomes also show that the overuse of $a$ was remarkably less in $[-\mathrm{S},-\mathrm{ESK}]$ environments than in $[+\mathrm{S}$, - ESK] environments ( $\mathrm{p}=.006)$. The Overuse of $a$ is shown to be more tied up with the negative value of ESK in combination with the positive rather than the negative value of specificity with the upper intermediate group.

\subsection{Results of the Intermediate Group}

Table 6. Intermediate Group's correct use of articles:

\begin{tabular}{lccccc}
\hline Definiteness & \multicolumn{2}{c}{-definite } & \multicolumn{2}{c}{+ definite } \\
Use of Article & \multicolumn{2}{c}{$\begin{array}{c}\text { Correct use of } a \\
\text { Mean } \%\end{array}$} & $S D$ & \multicolumn{2}{c}{ Correct use of the } \\
Context & 87.50 & .1410 & 66.18 & .2374 \\
\hline$[-$ spec; -ESK] & 83.82 & .2122 & 83.82 & .1935 \\
[+spec; +ESK] & 85.29 & .1642 & 52.21 & .2164 \\
\hline [+spec; -ESK] & & & & & \\
\hline
\end{tabular}

ANOVA found no difference among the three combinations in indefinite environments, $F(2,99)=.380, p=.685$, but significant effect for definite contexts, $\mathrm{F}(2,99)=18.206$, $\mathrm{p}<.001$. Multiple comparisons show that the correct use of the in [+spec; +ESK] environments is remarkably more than that either of [-spec; $-\mathrm{ESK}]$ environments $(p=.005)$ or of $[+$ spec; $-\mathrm{ESK}](\mathrm{p}<.001)$ environments, and there is significant difference between [+spec; $-\mathrm{ESK}]$ environments and $[-$ spec; - ESK $]$ environments $(\mathrm{p}=.033)$, favoring the latter.

Table 7. Intermediate group's overuse of articles

\begin{tabular}{|c|c|c|c|c|}
\hline \multirow{3}{*}{$\begin{array}{l}\text { Definiteness } \\
\text { Use of Article } \\
\text { Context }\end{array}$} & \multirow{2}{*}{\multicolumn{2}{|c|}{$\begin{array}{c}\text {-definite } \\
\text { overuse of the }\end{array}$}} & \multirow{2}{*}{\multicolumn{2}{|c|}{$\begin{array}{c}+ \text { definite } \\
\text { overuse of a }\end{array}$}} \\
\hline & & & & \\
\hline & Mean $\%$ & $S D$ & Mean \% & $S D$ \\
\hline [-spec; -ESK] & 3.68 & .0899 & 23.53 & .2127 \\
\hline$[+$ spec; +ESK $]$ & 14.71 & .2052 & 9.56 & .1848 \\
\hline [+spec; -ESK] & 7.35 & .1310 & 40.44 & .2220 \\
\hline
\end{tabular}

The outcomes exhibit that the overuse of the in indefinite environments was marginally influenced by the association of specificity and ESK values, $\mathrm{F}(2,99)=4.777, \mathrm{p}=.010$. Contrasts displayed that overuse of the in $[+$ spec; +ESK] indefinite environments was remarkably more than in [-spec; - ESK] environments, $(p=.003)$, but only marginally more than in [+spec; $-\mathrm{ESK}]$ environments $(\mathrm{p}=.046)$. The overuse of the in $[+\mathrm{spec},-\mathrm{ESK}]$ environments is more $(\mathrm{M}=7.35 \%)$ than that in $[-\mathrm{spec}$; $-\mathrm{ESK}]$ environments $(\mathrm{M}=3.68 \%)$, though not arriving at the significant level $(\mathrm{p}=.314)$, and the trend is predicted by Ionin et al.'s FH, confirming the argument that the overuse of the is connected with the minus value of specificity.

Overuse of $a$ in definite environments was also remarkably influenced by the association of specificity and ESK values, $\mathrm{F}(2,99)=18.957, \mathrm{p}<.001$. Multiple contrasts reveal that the overuse of $a$ was remarkably less in definite $[+$ spec; + ESK $]$ environments than in $[-$ spec; - ESK $]$ environments $(p=.024)$ and than in $[+$ spec, $-E S K]$ environments $(\mathrm{p}<.001)$. And the results also display that the overuse of $a$ was remarkably less in $[-\mathrm{S},-\mathrm{ESK}]$ environments than in $[+\mathrm{S},-\mathrm{ESK}]$ environments $(\mathrm{p}=.005)$. This is against our prediction that the overuse of $a$ 
would be connected with the minus value of specificity. The Overuse of $a$ is shown to be more tied up with the negative value of ESK in combination with the positive rather than the negative value of specificity with the intermediate group.

\section{Conclusion}

The present study questioned the FH and verified the SMA concerning English articles choice. The articles choice is affected by the objective identifiability of the referent rather than the article choice parameters. The variable specificity plays no role in L2ers' article option but the extra-linguistic factor \pm ESK (the statement or denial the familiarity/ acquaintance with the entity in question) influences a great deal for the L2ers to choose the articles. Moreover, the L2ers from L1 without articles maybe relate referential meaning of definite to the perceptible referent but the meaning of indefinite to the non-recognizable referent and thus produce substitution errors in English article choices, reflecting a pattern of overuse $a$ in context type where there is a [-ESK] feature and overuse the in context type in which there exists a [+ESK] feature.

In Ionin et al. (2004) and the current research, whether the definite contexts or the indefinite contexts should be considered as specific, once there lies an ESK part. Since that, the conclusion that the L2ers' article choice is influenced by the role of specificity and fluctuate between the article choice parameters definiteness and specificity can not hold water. What really counts in L2ers' article choice is the non-UG-based extra-linguistic factor: the L2ers explicitly stated or denied knowledge of the entities being talked about.

\section{References}

Berry, R. (1991). The English article system: Acquisition, function and pedagogy. Modern Language Journal, $75(2)$.

Chang Hui. (2009). The Study of Article Acquisition and Interlanguage Syntactic Impairment- the latest development of accessibility to UG. Foreign Languages, 32(6), 35-46.

Chomsky, N. (1981a). Principles and parameters in syntactic theory. In Hornstein and Lightfoot (Eds.).

Cook, V. (1985). Language Functions, Social Factors, and Second Language Teaching. IRAL, 13(3), 77-96.

Cook, V. (2002). Linguistics and Second Language Acquisition. Beijing: Foreign Language Teaching and Research Press.

Dai Weidong, \& Wei Li. (2008). The Study of Chinese Learners' Acquisition of English Article Semantic Features. Foreign Language Teaching and Research, 40(2), 136-142.

Ionin, T., Ko, H., \& Wexler, K. (2004). Article semantics in L2 acquisition: The role of specificity. Language Acquisition, 12, 3-70. http://dx.doi.org/10.1207/s15327817la1201_2

Master, P. (1987). A Cross-Linguistics Interlanguage Analysis of the Acquisition of the English Article System. Doctoral dissertation, University of California, Los Angeles.

Master, P. (1990). Teaching the English Articles as a Binary System. TESOL Quarterly, 24, 461-478. http://dx.doi.org/10.2307/3587230

Robertson, D. (2000). Variability in the use of the English article system by Chinese Learners of English. Second Language Research, 16, 135-172. http://dx.doi.org/10.1191/026765800672262975

Rod, Ellis. (1994). The Study of Second Language Acquisition (pp. 429-430). Oxford: Oxford University Press.

Trenkic, D. (2007). Variablity in L2 article production: Beyond the representational deficit vs. processing $\begin{array}{llll}\text { constraints debate. Second } & \text { Language Research, }\end{array}$ http://dx.doi.org/10.1177/0267658307077643

Trenkic, D. (2008). The representation of English articles in second language grammars: Determiners or adjectives? Bilingualism: Language and Cognition, 11(1), 1-18. http://dx.doi.org/10.1017/S1366728907003185 